\title{
Supervised discharge orders in England
}

\section{Compulsory care in the community}

\author{
Vanessa Pinfold, Jonathan Bindman, Karin Friedli, Andrew Beck \\ and Graham Thornicroft
}

\begin{abstract}
Aims and method Supervised discharge orders were introduced in April 1996. This paper describes two national surveys of their use in all mental health provider trusts in England. Data were collected from key informants in mental health provider trusts using a postal survey in 1997, and a follow-up telephone survey in 1998.

Results The total number of patients subject to supervised discharge in 1997 was 160, a mean of one per trust. In 1998, there were 378 cases, a mean of two cases per trust. The annual period prevalence in 1998 can be estimated as 510 cases, approximately one per 100000 total population per year. Seventeen applications of the 'power to convey' were identified. Clinical implications Supervised discharge is regarded as sultable for very few patients, though its use is growing. The controversial power to convey is seldom used in practice and barriers to its use are described.
\end{abstract}

The Mental Health (Patients in the Community) Act 1995 amended the Mental Health Act 1983 and provided a new power termed 'supervised discharge' which came into effect from 1 April 1996. The Department of Health (1993a) estimated that two-thirds of compulsory admissions, approximately 3000 at any point in time, would be suitable for compulsory supervision under supervised discharge. However, the order has been criticised on the grounds that while it infringes patients' civil liberties and risks damaging therapeutic relationships, it fails to provide effectively for compulsory adherence to treatment (Thompson, 1995) and use might therefore be very low (Holloway, 1996). This study describes the use of supervised discharge throughout England two years after its introduction and presents data from key informants concerning the implementation of the order.

\section{The study}

A national postal survey of all adult mental health provider trusts was conducted in 1997 as part of a larger study, and a telephone survey of the use of supervised discharge was conducted in 1998. Data were collected from key informants in every adult mental health provider trust in England. A database of trusts was established initially using the NHS Executive's Quarterly Monitoring Report for the third quarter of $1995 / 1996$, and was updated by direct contact with trusts prior to the surveys. Contact with other potential users of the order was also made but use was minimal, and only NHS adult mental health providers in England are considered further in this paper.

For the 1997 survey, the larger study required the selection of informants with knowledge of the implementation of Care Programme Approach policy and an appropriate administrator, Care Programme Approach coordinator or other senior manager. These individuals also supplied data on supervised discharge use. For the 1998 survey, initial contact was made with the same individuals although in 83 trusts $(47 \%$ valid cases) the appropriate post-holder had changed. Survey data were collected over a six-month period to June 1997, and over a three-month period to June 1998. In 1997 the number of individuals subject to supervised discharge was sought. In 1998 questions on appeals, the use of specific powers included in the order, and other aspects of its use were collected. Where supervised discharge had not been used the reasons for this were explored. Informants' responses were recorded verbatim by a researcher (V. P.) for content analysis.

The enumeration data were entered into a computerised database and analysed using SPSS (version 6.0). The data were skewed, and the Wilcoxon rank-sum test was applied to test for increases in use between the two survey periods. Spearman's rank correlation was used to examine the association between rates of supervised discharge use in trusts and rates of patients subject to the Care Programme Approach. Supervision Register and Section 3 of the Mental Health Act. 
The content of informant responses was systematically coordinated and coded within Microsoft Word and analysed to identify emergent themes, a process which is described by Robson (1994). Initial codes are used to fracture qualitative data into categories, and these are subsequently refined to most effectively describe the emergent themes within the data. The data were coded twice by one researcher and once by another member of the research team (Bowling, 1997). Three sets of data were analysed: views of the order within trusts, problem encountered in its application, and the use of the power to convey.

\section{Findings}

Supervised discharge: use of the order

In 1997, 180 trusts were identified as providing adult mental health services in England and data were obtained from $165(91.7 \%)$. In 1998, there were 179 trusts and data were obtained from 178 $(99.4 \%)$. In 1997 , approximately one year after the introduction of supervised discharge, informants reported 160 individuals subject to the order at the time of completing the survey (Table 1). The median number of cases was one and 76 trusts ( $46 \%$ valid cases) had no patients subject to the order. By 1998 the number of cases had increased to 378 (significance of increase $z=5.49$, $P<0.001)$. Sixty-five trusts ( $36 \%$ valid cases) had no patients subject to the order and this included seven trusts $(4 \%)$ which had reported cases in 1997. Of the trusts responding to both surveys 45 had no cases at either time point; 19 (11\%) had used it during the intervening period and 26 (15\%) had not. In 1998 the three trusts with the largest number of cases reported 29, 24 and 17 cases respectively. These 70 cases represent $18.5 \%$ of the national total.

In addition to the cases reported at the survey points, a further 132 orders were reported as having been initiated and discharged in the course of the year 31 March 1997-1 April 1998. The annual period prevalence for the year prior to the second survey can therefore be estimated as 510 cases, approximately one per 100000 total population per year. There was no significant correlation between rates of supervised discharge in individual trusts and those of patients subject to the Supervision Register, detained under Section 3, or reported by trusts as on the Care Programme Approach.

\section{Appeals}

Informants reported 33 appeals against the order in 26 trusts. Twenty of these had been heard by a Mental Health Act tribunal, which had discharged the order in only one case.

\section{Perceptions of supervised discharge}

General comments were provided by the informant from 143 trusts $(80.3 \%)$. A total of 412 comments were coded and 35 themes were identified. The seven themes identified by at least 20 informants are shown in Table 2; they account for $60.1 \%$ of the general responses.

The two themes most commonly expressed by informants were that supervised discharge is powerless (62/143 trusts, $43 \%)$ and that existing legislation is sufficient for clinical needs $(29 \%)$. These themes are linked because the lack of powers to enforce treatment requires the re-use of Section 3 of the Mental Health Act. It was also suggested that the lack of power to directly effect compliance was a reason for not applying the order.

The order was, however, also perceived to have positive effects (see Table 2, Themes 3, 4 and 6):

"Orders have been effective in terms of maintenance of medication and patients mental health. Patients functioning in the community on the order has improved".

"Supervised discharge has been a useful monitoring tool - if people do relapse we have got in earlier, it

Table 1. Use of supervised discharge orders in 1997 and 1998

\begin{tabular}{lll}
\hline & $\begin{array}{l}\text { Supervised Discharge } \\
\text { Orders } 1997\end{array}$ & $\begin{array}{c}\text { Supervised Discharge } \\
\text { Orders 1998 }\end{array}$ \\
\hline Number of respondents & 165 & 178 \\
(\% of mental health trusts) & $(91.7)$ & $(99.4)$ \\
Number of orders & 160 & 378 \\
Mean (s.d.) & $0.97(1.23)$ & $2.12(3.55)$ \\
Median (25th and 75th percentile) & $1(0-2)$ & $1(0-3)$ \\
Range & $0-7$ & $0-29$ \\
Per 10000 population & & $0.74(1.04)$ \\
Mean (s.d.) & $0.42(0.6)$ & $0.42(0-1.06)$ \\
Median (25th and 75th percentile) & $0.3(0-0.73)$ & $0-6.84$ \\
Range & $0-3.53$ & \\
\hline
\end{tabular}




\begin{tabular}{|c|c|c|c|}
\hline \multirow[b]{2}{*}{ Main themes } & \multicolumn{3}{|l|}{ Strength of theme } \\
\hline & No. of comments & $\begin{array}{l}\text { \% of comments } \\
(n=412)\end{array}$ & $\begin{array}{l}\% \text { trusts } \\
(n=143)\end{array}$ \\
\hline $\begin{array}{l}\text { (1) Supervised discharge is powerless e.g. Can not } \\
\text { enforce treatment, can not influence non- } \\
\text { compliant patients, results in re-sectioning } \\
\text { and therefore it is a waste of time }\end{array}$ & 62 & 15.0 & 43.3 \\
\hline $\begin{array}{l}\text { (2) Supervised discharge doesn't add anything extra } \\
\text { to what is already available under the Mental } \\
\text { Health Act and Care Programme Approach } \\
\text { process e.g. Prefer use of guardianship. Section } \\
17 \text { extended leave and Section } 117 \text { aftercare } \\
\text { with assertive outreach }\end{array}$ & 42 & 10.2 & 29.4 \\
\hline $\begin{array}{l}\text { (3) Supervised discharge helps the review and } \\
\text { monitoring process }\end{array}$ & 38 & 9.2 & 26.6 \\
\hline $\begin{array}{l}\text { (4) Supervised discharge affects service user's } \\
\text { behaviour positively }\end{array}$ & 34 & 8.3 & 23.8 \\
\hline $\begin{array}{l}\text { (5) The bureaucratic 'paper chase' and procedural } \\
\text { issues affect use of the order e.g. Timing or transfer } \\
\text { of patients, coordination of review meetings, } \\
\text { difficulties in getting GP's involved }\end{array}$ & 32 & 7.8 & 22.4 \\
\hline $\begin{array}{l}\text { (6) Framework and structure of supervised discharge } \\
\text { is helpful }\end{array}$ & 20 & 4.8 & 14.0 \\
\hline $\begin{array}{l}\text { (7) Supervised discharge is only effective for a small } \\
\text { number of service users }\end{array}$ & 20 & 4.8 & 14.0 \\
\hline
\end{tabular}

The examples which appear in italics after a theme are explanatory comments made by informants to clarify responses.

hasn't taken so long for them to become stabilised". "The responsible medical officer seems to be pleasantly surprised by how patients on the order are more compliant with treatment because they recognise the framework of the law".

Some informants made both positive and negative comments, and emphasised the variability of individual responsible medical officers' experience and practice. Another explanation for the low frequency of supervised discharge use was also offered:

"It seems to be effective for a very small number of clients with .... non-compliance but they are also people who: (i) buy into the Mental Health Act using tribunals and appeals . . . and (ii) people who accept the powers over them".

Perceptions of specific problems arising in the implementation of supervised discharge

Informants were also asked to comment on problems arising in the use of the order. Content analysis of the 127 comments made by respondents from 79 trusts showed that the principal perceived problem with supervised discharge (65\% of comments) was the bureaucratic nature of procedures, described as cumbersome and involving excessive paperwork. Though procedural issues were mentioned mostly as a barrier to use, it was also pointed out that the complexity of the process can be beneficial, resulting in a fuller consideration of the order than might be the case for other sections of the Mental Health Act.

\section{Use of the 'power to convey'}

The power to convey is a distinguishing feature of supervised discharge, much discussed before the introduction of the legislation (Hampson \& Davidson, 1994; Eastman, 1995; Holloway, 1996; Rogers, 1996; Coffey, 1996). Informants from 127 trusts commented on the use of the power to convey. At 93 trusts (73\%) the power had not been used at all and at $21(17 \%)$ the informant was unsure. In only 13 trusts (10\%) was the power known to have been used, on a total of 17 occasions. These involved the uses envisaged in the legislation, enforcing the power to require residence, and conveying for the purpose of medical treatment, occupation, education or training. The power had also been used to enforce discharge from hospital and to convey people to hospital for assessment. One informant also reported that: 
“... the power to convey has been used but not in the sense that it is written into the act ... clients know if they do not attend the day centre someone will come to them and take them ... supervised discharge is a pass book to a free lift. so they are running rings around us."

Although the power had been little used, it was noted that some patients' awareness of the potential for its use might have resulted in improved compliance with treatment. It was also pointed out that because of concerns over the practicalities of conveying patients, a multidisciplinary review might be preferred to actual use of the power if the need for it appeared to arise.

\section{Discussion}

The point prevalence of supervised discharged cases, 0.7 per 100000 total population (25th and 75th percentiles 0-1.06) in 1998, and the estimated annual period prevalence, 1.0 per 100000 , are small in comparison with other measures of prevalence of cases of severe mental illness requiring supervision, such as the 8.6 patients per 100000 total population (25th and 75th percentiles 2.9-10.8) placed on Supervision Registers at the time of our 1997 survey (Bindman et al, 1998), and the annual period prevalence of 17.4 per 100000 (25th and 75th percentiles 8.8-21) population admitted to hospital under Section 3 of the Mental Health Act in 1996-1997 (Department of Health, 1998).

The application of supervised discharge to only a small fraction of those who might be considered to benefit from additional legal constraints (Department of Health, 1993a) might be taken as demonstration of the failure of a piece of legislation criticised at its introduction as being ill-considered (Hampson \& Davidson, 1994; Eastman, 1995: Dean, 1995; Holloway, 1996). However, the level of use is rising, and given the relative complexity of the measure it may be some years before trusts and clinicians become familiar with it and an optimal level of use is achieved.

A strength of the current study is its national coverage and high response rates. The data from informants cannot be taken as a direct indication of the effectiveness of supervised discharge because informants are heterogeneous, and they are expressing opinions which may be based on limited, or no clinical experience of applying the order. They are, however, a senior and well informed group and it was clear that supervised discharge has been the subject of widespread discussion and concern within the trusts. The data serve to confirm that negative views about the measure expressed during the passage of the legislation are in fact widespread throughout trusts nationally, and these views are likely to have a significant impact on the use of the order. It also appears that now the order is in place it is possible to observe ways in which it may have benefits for individual service users.

The power to convey was the subject of considerable discussion during the passage of the legislation. It was intended that the power to enforce attendance for treatment, the lack of which has been seen as a limitation of guardianship (Department of Health, 1993b), would be valuable even in the absence of a power to enforce treatment. The process of conveying would give the patient who was reluctant to comply, sufficient opportunity to consider the options so that: "by the time he (or she) has reached the destination for treatment, employment, education or whatever, it is likely that he (or she) will have recovered his (or her) feelings about the programme and go forward with it" (Bowis, 1995). Our data suggests that the practical difficulties of conveying an unwilling patient have resulted in the order being used very rarely.

The data suggests that it is possible that supervised discharge will be used for only a small fraction of those patients who give rise to particular concerns among their professional carers. It is possible however that a study of individuals subject to compulsory supervision will reveal identifiable subgroups of patients who can be more effectively treated using its powers. As the current Mental Health Act comes under review (Dobson, 1998) an understanding of the uses of supervised discharge and barriers to its use will indicate directions for future legislation.

\section{Acknowledgements}

A study of supervised discharge and guardianship is being undertaken by PRiSM at the Institute of Psychiatry, University of Manchester School of Psychiatry and Behavioural Sciences and St George's Hospital Medical School, who received funding from the Department of Health.

\section{References}

Bindman, J., Beck, A. \& Thornicroft, G. (1998) National Evaluation of Supervision Registers: Report of Study Commissioned by the Department of Health. London: PRISM, Institute of Psychiatry.

Bowis. J. (1995) Orders of the Day: Mental Health (Patients in the Community) Bill. Hansard, 20 June. London: HMSO.

Bowung, A. (1997) Research Methods in Health Buckingham: Open University Press.

COFFEY, M. (1996) Supervised discharge. Nursing Times, 92, 50-52.

DEAN, M. (1995) Alarm over supervised discharge orders. Lancet. 345. 573. 
DePaRTMENT OF HEALTH (1993a) Legislation Planned to Provide for Supervised Discharge of Psychiatric Patients. Virginia Bottomley Announces 10-Point Plan for Developing Successful and Safe Community Care. London: Department of Health.

- (1993b) Legal Powers on the Care of Mentally III People in the Community. Report of the Internal Review. London: Department of Health.

- (1998) In-patients Formally Detained in Hospitals under the Mental Health Act 1983 and other Legislation. London: Department of Health.

DoBson, F. (1998) Frank Dobson Outlines Third Way for Mental Health. http://www.coi.gov.uk/coi/depts/ GDH.

EASTMAN, N. (1995) Anti-therapeutic community and mental health law. British Medical Journal, 310. 1081-1082.

HAMPSON, S. \& DAvidson, P. (1994) Proposed new legislation for the care of mentally ill people in the community. Opinions of psychiatrists and social workers. Psychiatric Bulletin, 18, 726-729.

HoLLOWAY, F. (1996) Supervised discharge - paper tiger. Psychiatric Bulletin. 20, 193-194.
NHS EXECUTTVE (1996) Quarterly Monitoring Report for the Third Quarter of 1995/1996. Leeds: NHS Executive.

Robson, C. (1994) Real World Research: A Resource for Social Scientists and Practitioner Researchers. Oxford: Blackwell.

RoGERS, B. (1996) Supervised discharge: implications for practice. Mental Health Nursing, 16, 8-10.

THOMPSON. C. (1995) New powers for care of the mentally ill. p. 17. The Times, 23 March.

*Vanessa Pinfold, Research Worker, Jonathan Bindman, Lecturer, Karin Friedli, Project Coordinator, Andrew Beck, Research Worker and Graham Thornicroft. Professor of Community Psychiatry. Section of Community Psychiatry (PRISM), Institute of Psychiatry, De Crespigny Park, London SE5 8AF

*Correspondence

\title{
Experience and application of HoNOS65+
}

\author{
Lesley Allen, Sushila Bala, Richard Carthew, Stephanie Daley, \\ Eugene Doyle, Pat Driscoll, Barbara Grey and Alastair Macdonald
}

Aims and method The implementation of the Health of the Nation Outcomes Scales for Old Age Psychiatry services (HoNOS65+) in a National Health Service trust is described. Some preliminary data are reported for illustrative purposes.

Results Lessons learnt from this process are identified, and further work needed both on the glossary for the scales and on systems for trapping data is suggested. Clinical implications These remain uncertain. It may be that HoNOS65+ will remain a purely administrative tool.

The HoNOS (Health of the Nation Outcome Scales) were devised, with funding from the Department of Health, by the Royal College of Psychiatrists Research Unit (CRU) in order to measure global change in the health and social functioning of mentally ill people (Wing et al, 1996). The primary aim of the scales was that they be used by multi-disciplinary clinicians in the mental health field to help achieve one of the three targets for improving mental health identified in the Government's Health of the Nation strategy - namely "to improve significantly the health and social functioning of mentally ill people". The CRU made it clear that they considered this to include: improvement in mental, physical and/or social functioning, over and above what would be expected without intervention; and maintenance of an 'optimal functional state' by preventing, slowing and/or mitigating deterioration.

In the development of HoNOS, the CRU completed four stages of work:

(a) Start-up phase, which included a literature search, and the first draft of the score, which included 20 items, one global, each rated 0-3.

(b) Two pilot projects were set up, whereby data and user comments were analysed by the CRU. Changes to the scales included a reduction to 12 items, a more detailed glossary and 0-4 rating points. 